\title{
Caligrafía de los sueños y el universo Marsé'
}

\section{Caligrafia de los sueños and the Marsé universe}

\author{
JUAN CARLOS RODRÍGUEZ \\ Universidad de Granada \\ España \\ jcrodri@ugr.es
}

Plantearemos tres preguntas:

1.- ¿Cómo se puede crear un universo?

2.- ¿Cómo se escribe una novela?

3.- ¿Cómo se escriben los sueños? ${ }^{2}$

$\mathbf{I}^{\mathbf{0}}$.- Comencemos por la segunda pregunta: ¿cómo se escribe una novela? Es facilísimo. Y nos lo enseñó Cervantes que es el padre de todo esto. Don Quijote se inventa a sí mismo y se escribe a sí mismo cada día. Cada día también nosotros nos escribimos a nosotros mismos y nos inventamos nuestra propia vida. El problema es desde qué inconsciente nos escribimos. Y lo realmente difícil es trasladar eso al papel o a la pantalla del ordenador. Especialmente difícil es la tarea de tachar y borrar, de revisar y corregir, al igual que hacemos nosotros al escribirnos.

$\mathbf{2}^{\mathbf{0}}$.- Vayamos ahora a la primera pregunta: ¿cómo se puede crear un universo? Ideológicamente crear un universo sin haberlo experienciado antes, sin haberlo vivido antes, eso sólo lo puede hacer Dios. Pero ideológicamente asimismo Kant señaló que eso podían hacerlo los hombres a través de los juicios sintéticos a priori.

Un juicio sintético a priori significa crear un mundo que no se ha experienciado previamente.

Aquí viene el problema: si todos los/ las novelistas escriben desde su presente, y escri-

\footnotetext{
I Para citar este artículo: Rodríguez, Juan Carlos (2012), “Caligrafía de los sueños y el universo Marsé”. Álabe 6. [www.revistaalabe.com]

(Recibido I4-II-2OI2; aceptado I4-II-2OI2)

${ }^{2}$ Conferencia pronunciada en la Casa de las Mariposas (Almería), Julio, 2OII
} 
ben sobre el pasado, el presente y el futuro (digamos los de ciencia/ ficción, que trasladan el presente al futuro), si eso es así, ¿cómo no van a haber experienciado el mundo que nos cuentan?

Efectivamente lo han hecho, han experienciado el mundo que crean, pero nos lo cuentan transformándolo, como si fuera nuevo (aunque con los suficientes datos como para que lo reconozcamos o nos identifiquemos con ese mundo). A eso lo he llamado -no es difícil- la ideología del junto $a$. También podría llamarse “juicios analíticos” a posteriori, pero habría que matizarlo mucho y -de cualquier modo- llegaríamos a la misma conclusión. "Junto a" lo que uno ha vivido existe la transformación. Y esa transformación de lo vivido se convierte en un juicio sintético a priori: no como si fuera un universo creado por Dios sino mucho más sencillamente como si fuera un sueño o una realidad re-vivida, producida o creada de nuevo. De hecho cada novela despliega una concepción del mundo, despliega una escritura que en el fondo es un juicio sintético a priori que se va realizando en la práctica. Lo cual no implica que la novela siga siempre en absoluto las intenciones del autor, implica, al contrario, que la escritura puede vivir por sí misma, desplegarse por sí misma: son las famosas contradicciones que constituyen a la literatura.

$3^{\mathbf{0}}$ - Llegamos así a la pregunta final: ¿cómo se escribe un sueño?

Freud nos indica que existen sueños diurnos y nocturnos. Nosotros nos escribimos diariamente despiertos y dormidos. Y es así como nos leemos (y como leemos las novelas de nuestra novela diaria). Nos escribimos inconscientemente -ideológicamente- a través de lo que queremos ser (lo que se llama el yo ideal), pero también nos escribimos -ideológicamente- a través de nuestro inconsciente pulsional (lo que se llama el ideal del yo, de alcanzar un yo). O sea, a través de lo que quizá seamos pero no queremos ser. Por eso, añade Freud, en el trabajo del sueño, en la elaboración de su escritura, actúan dos mecanismos:

I) El contenido latente (que es lo que más o menos no se ve claro en los sueños) y, por otro lado, el contenido manifiesto (que es lo que más o menos se ve claro en los sueños diurnos o nocturnos). Evidentemente el contenido manifiesto nos suele engañar, y por eso hay que ir más al fondo.

2) Para ir más al fondo tenemos que tener en cuenta que el sueño concentra sus temas y a la vez los desplaza. Concentración y desplazamiento se han entendido también de forma narrativa: el desplazamiento sería la metonimia (digamos la parte por el todo, lo verdaderamente narrativo) y la concentración sería la metáfora (digamos la sustitución de una imagen, una idea o una palabra por otra cosa aparentemente distinta. Por ejemplo comparar los labios de una chica con los pétalos de una rosa es quizá la metáfora más clásica que existe. Al primero que se le ocurrió se le puede considerar un genio, luego ya las cosas varían en cada comparación). Supongamos que es el trasfondo alegórico de la narración. 
Ahora bien: ni el inconsciente ideológico de Marx ni el inconsciente pulsional de Freud nos explican cómo nuestros sueños o nuestra novela diaria se trasladan al papel o a la pantalla, cómo se despliega en la práctica un juicio sintético a priori.

Y sin embargo todos los grandes novelistas (digamos del siglo XX, que es el más próximo) han escrito sus obras a través de juicios sintéticos a priori junto a la ideología de la transformación en la práctica. Es decir, han transformado su mundo en un mundo nuevo para conseguir que lo viviéramos por primera vez. E incluso a veces le han dado un nombre nuevo o han conseguido que sus mundos tengan para nosotros un significado nuevo:

Así el París de Proust es un mundo nuevo respecto al París que conocemos; así el Dublín de Joyce es un mundo nuevo respecto al Dublín que conocemos; y lo mismo ocurre con el Sur de los Estados Unidos en Faulkner o con la imagen de la Ley en Kafka, con el Macondo de García Márquez, con el Santa María de Juan Carlos Onetti o con el México de Juan Rulfo.

Y así ocurre con la Barcelona (y en especial con los barrios del Guinardó y el Carmelo) de Juan Marsé.

Sólo que Marsé sí nos ha mostrado la elaboración directa de los sueños: precisamente a través de la narración de las aventis, las aventuras o los cuentos que se narran los niños (y los adultos). Como en los sueños, esas aventis concentran un mundo (y un grupo de amigos) y a la vez lo desplazan hacia todas las partes del mundo.

Y esa es la lógica del universo de Marsé.

Pero indiquemos algo más. Contar historias allí donde la historia se nos presenta como detenida o muerta puede parecer un absurdo, salvo que esa sea la única manera de tener historia. Eso fue precisamente lo que hizo Juan Rulfo con las dos obras que dedicó al tiempo final de la revolución mexicana: una revolución que nació muerta y donde finalmente sólo hablan los muertos, como en la novela Pedro Páramo (I955) o en el anterior libro de cuentos El llano en llamas (1953). En el universo de Juan Marsé, especialmente el de los años 40 y 50 del franquismo, los muertos también hablan pero lo hacen a través del silencio de los vivos o de los fantasmas de la realidad en que se vive, una realidad no menos fantasmática y sobre todo inmóvil.

Sólo que bajo ese mundo fantasmal e inmóvil, van apareciendo unos gusanitos, unos calabacines con patas, que son los niños, los niños que se inventan otra realidad más viva y más auténtica para ellos: son los kabileños, los hijos de los charnegos, de los emigrantes que viven en esos barrios del Carmelo y del Guinardó en la Barcelona mísera de la posguerra, unos chicos que oscilan entre los diez y los quince años (como máximo) y que se inventan su propia vida a través de las aventis: esas aventuras contadas entre ellos en las que ellos participan de un modo u otro. Gracias a esas historias, gracias a las aventis, los niños se crean sus propios sueños, adquieren otro espejo donde reflejarse y desde donde mirar el mundo negro e imposible que los rodea.

Analizaremos esa Caligrafía de los sueños de los niños en la última y extraordinaria novela publicada por Marsé. Pero hay otra línea paralela en las obras de Marsé: pre- 
cisamente los sueños o las imposturas de los adultos, de las mujeres y los hombres que viven en el arriba y el abajo de la ciudad. Pues no sólo se intercambian ambos espacios, sino también los tiempos: si las sombras y las pesadillas de la infancia las sitúa Marsé en los años cuarenta y cincuenta del franquismo, por el contrario -y por lo general- las sombras y las pesadillas de los jóvenes y los adultos las sitúa Marsé en los años sesenta y setenta e incluso los últimos libros ya en la transición democrática, o sea, en el tiempo real en que escribe sus obras.

Y así ocurre en su trayectoria novelística:

Marsé nació en Barcelona en I933, fue finalista del Premio Biblioteca Breve de la editorial Seix Barral, en I96o, con la novela Encerrados con un solo juguete, un texto con ribetes autobiográficos, donde los hijos de los perdedores de la guerra no tienen más expectativas que estar encerrados en sí mismos y en un mundo imposible, no tienen más juguete a la vista que el que pueden imaginarse, es decir, el sexo. Aunque la novela tuvo al parecer más votos que ninguna, el premio quedó desierto. Pero según recuerda Josep María Castellet poco después Marsé se fue a Paris con una beca para formarse mejor cultural y literariamente. En París estuvo trabajando de ayudante de laboratorio en el Instituto Pasteur, mientras que antes había trabajado en un taller de joyería en Barcelona.

Al parecer fue en París donde fraguó las primeras imágenes o el primer esquema de Últimas tardes con Teresa. Pero al regresar dos años después, en ig62, Marsé publica una segunda novela a la que tituló Esta cara de la luna. Sinceramente debo decir que ninguna de estas dos primeras novelas (Encerrados con un solo juguete y Esta cara de la luna) me han dejado de gustar nunca, pero ignoro los motivos por lo que Marsé ha impedido siempre la reedición de su segunda novela. Nunca ha querido volver a saber nada de Esta cara de la luna. Quizá no la encontró literariamente cuajada o quizá no gustó al grupo intelectual que Carme Riera ha llamado Escuela de Barcelona, donde además de Castellet figuraba sobre todo el "círculo" de Carlos Barral, Joan Petit, Joan y Gabriel Ferrater, J. M. Valverde, Rosa Regás, Luis y José Agustín Goytisolo, y en especial su gran amigo Jaime Gil de Biedma (y también los “foráneos” como Ấngel González, Juan García Hortelano, J. M. Caballero Bonald, etc.).

Fuera por las razones que fuera lo cierto es que Marsé se decidió a fraguar finalmente aquel otro esquema también imaginado en París, el libro que se iba a convertir en su primer gran éxito y que iba a convertir a Marsé en novelista de primera fila. Es decir, Últimas tardes con Teresa, que obtuvo el Premio Seix Barral, en i965 y que se editó -por problemas de censura- en I966. La novela arrastra un flujo vital y narrativo increíble, aunque las figuras de sus protagonistas fueran quizá mal entendidas por algunos críticos de entonces: tanto la figura de Teresa Serrat, la joven universitaria burguesa izquierdista, como el charnego Manolo Reyes, el Pïoaparte, al que Teresa y su grupo confunden con un obrero revolucionario. Pero aquellas críticas se pueden ver hoy como absolutamente desenfocadas. Puesto que la novela leída desde ahora nos muestra sin más la realidad de una doble impostura: los sueños idealizantes de Teresa y los sueños del Pijoaparte haciéndose pasar por lo que no es; y todo ello acaba por convertirse no en una crítica de 
nada sino en la visión palpable de que en una realidad de imposturas todo el mundo se vuelve impostor. Y sintomáticamente esa cuestión del mundo impostor y de los personajes impostores seguirá atravesando las obras de Marsé, donde sólo los sueños inventados de los niños son reales y auténticos. De cualquier modo en el prólogo a la séptima edición de la novela, diez años después, Marsé reivindicará ante todo ese flujo vital que subyace en el texto, más allá de los supuestos arquetipos de los protagonistas.

Manuel Reyes, el Pijoaparte, reaparecerá cinco años después, en la novela siguiente titulada La oscura historia de la prima Monse, una novela que a mí me gustó muchísimo, porque aquí la historia es realmente trágica. Monse conoce a Manuel en la cárcel, en una visita caritativa, pero su represión religiosa la lleva a una solución fatal. Todo es triste y bastante miserable en la degradación de esa relación amorosa contada por la hermana de Monse (Nuria) y especialmente por su amante Paco Bodegas (que funciona como una especie de alter ego del propio Marsé, en tanto que narrador).

Pero a partir de aquí, a partir de I970 y de su consolidación como novelista, Marsé decide hacer el camino a la inversa: no subir a los charnegos hacia arriba sino bajar él mismo a su mundo de la infancia y la adolescencia, al mundo del Guinardó y el Carmelo.

Y así comienza el gran universo de las aventis.

Y así también comienza el laberinto de Si te dicen que caí. Ya el título, que es un verso del himno de la Falange, indicaba la imposibilidad de ser publicada en España. Pero Marsé la terminó en su primera versión en I973. Y tenía dos problemas, la censura, como decimos, y la propia estructura de la novela. Sencillamente el extraordinario narrador que es Marsé había hecho una novela tan “compleja y ensimismada” - como el propio Marsé dirá después- que su estructura parecía desencajada y con partes en sombra o de sobra. Marsé nos cuenta lo que ocurrió en la nota que antecede a la versión corregida y definitiva fechada en r988-89. Puesto que era imposible publicarla en España, alguien le habló del Premio Internacional de Novela México. Marsé ganó el premio y la novela se editó en México, en la editorial Novara, sin corregirla y sin revisar las galeradas. Muerto Franco, se editó en r976 en Seix Barral, pero era la misma versión de México, ahora no corregida por indolencia del propio Marsé, según él nos cuenta. Hasta que llegó la versión del 89, la definitiva. Ahora a la novela le faltan dos capítulos no suprimidos sino integrados en otras partes y la estructura se ha vuelto explícita y transparentemente magnífica: un rico industrial barcelonés aparece ahogado en el mar en su Simca I2Oo de primera clase, junto a su mujer y sus dos hijos pequeños. Ha sido un accidente mortal al intentar adelantar el coche de una chica. Y Ñito Marés (o sea, Juanito Marsé), que trabaja ahora en el depósito de cadáveres de la Facultad de Medicina, lo identifica como su amigo el Java, Daniel Javaloyes, el niño trapero y el que mejor contaba las aventis entre los chicos de la zona del Guinardó, etc. Junto al Java y el Sarnita (o sea, Marsé), estaban el Tetas, Luis, Amén, Martín y, oh sorpresa, Mingo, el mismo Mingo o Ringo que será protagonista de Caligrafía de los sueños. Y además Mingo aparece igual que en la última novela: con el brazo en cabestrillo y con la bufanda cruzándole el pecho como una doble canana. Luego, en Caligrafía de los sueños, Mingo se convertirá en Ringo, en recuerdo del héroe de La 
Diligencia, la película en que John Ford (basándose en un relato de Maupassant, Bola de sebo) creó de verdad el género del Oeste en el cine, y la película que lanzó al estrellato a John Wayne, el verdadero Duque para el público norteamericano.

Y también para estos niños de las aventis: pues para estos niños todo es cine, incluidos por supuesto los cines con nombre (el Roxy, el Delicias, el Verdi) y sus películas de sesión continua; a la vez que todo son tebeos (El guerrero del antifaz, Jorge y Fernando, Rip Kirby), o novela de quiosco, como El Coyote, de J. Mallorquí y La sombra (también traducida por Mallorquí) o las escritas por autores españoles con pseudónimo, como González Ledesma (Silver Kane) o Alf Manz, etc. Las aventis, decíamos, parten de un suceso más o menos real que se transforma en múltiples aventuras que no acaban nunca. En medio de una atmósfera de un erotismo durísimo, a la vez que triste, en la novela también hay historias de anarquistas perdidos y atracadores frustrados, o mejor, esa frustración total, esa desesperanza oceánica, de que habla Marsé, que lo ha paralizado todo, como la despedida final de dos viejos amigos en una estación del Metro, una despedida tras la que Marsé concluye: "Hombres de hierro, forjados en tantas batallas, soñando como niños”. En la nota de i988, Marsé nos cuenta a propósito de Si te dicen que caí: “Pensaba solamente en los anónimos vecinos de un barrio pobre que ya no existe en Barcelona, en los curiosos muchachos de la posguerra que compartieron conmigo las calles leprosas y los juegos atroces, el miedo, el hambre y el frío; pensaba en cierto compromiso contraído conmigo mismo, con mi propia niñez y mi adolescencia, y en nada más”.

Y así comprendemos plenamente el trasfondo que existe tras esos sueños reales, esas aventuras de los niños perdidos que se viven a sí mismos como aventureros imposibles. O quizá luego no tan imposibles, porque desde ese mundo surgió inesperadamente, como saltando de una de las aventis, un detective real: el Pepe Carvalho de Vázquez Montalbán, con Tatuaje, de I974 (el título era un homenaje obvio, a través de la canción de Concha Piquer, a lo que el propio Vázquez Montalbán, en una serie de artículos en la revista Triunfo y luego como libro suelto, llamó Crónica sentimental de España); luego la serie de Carvalho continuaría con dos espléndidas novelas en los años 7o: La soledad del manager, de 1977 y Los mares del sur, del 79 (con Charo, Bromuro, Biscuter y la cocina como personajes inevitables) y llegaría hasta Milenio. La amistad que unió siempre a Marsé y a Vázquez Montalbán, así como los elogios que Vázquez Montalbán dedicó siempre a las novelas de Marsé y en especial a Si te dicen que caí, todo eso provenía de ese mundo de niños charnegos, miserables, con infancias similares (Marsé en el Carmelo y Vázquez Montalbán cerca del Barrio Chino), pero repito que Carvalho parece un personaje salido de las aventis, solo que convertido en realidad posible porque a fines de los años zo la novela negra era ya posible en España (en la España de Franco sólo había orden, no había crímenes, salvo las locuras que se contaban en la revista El caso3). Al igual que tampoco existía una verdad histórica del pasado como la que deslumbró al público con la novela La verdad sobre el caso Savolta, de Eduardo Mendoza, de I975, otro síntoma extraordi-

\footnotetext{
3 Sólo se podía ofrecer un crimen en cada número de El caso.
} 
nario de los nuevos tiempos. Con una observación clave: en Si te dicen que caí, la chica/ puta Aurora (o Ramona) y Marcos, el marinero rubio hermano del Java, parecen sacados directamente de esa canción de Concha Piquer, Tatuaje, el título que recuperará Vázquez Montalbán al año siguiente de Si te dicen que caí.

Pero si Pepe Carvalho (más Chandler que Hammett), había nacido del mundo de los sueños infantiles del cine y de las novelas de aventuras, Juan Marsé por su parte abandona momentáneamente ese mundo para escribir La muchacha de las bragas de oro (un título quizá vagamente inspirado en Balzac: La muchacha de los ojos de oro) novela con la que ganó el Premio Planeta en I978. Se trata de la historia de una nueva impostura: la de los intelectuales falangistas que al llegar la transición se convierten de repente en demócratas, o tratan de demostrar que lo han sido prácticamente siempre. Sus dardos se dirigen contra el barcelonés Luys de Santamarina y contra Pedro Laín Entralgo y su libro Descargo de conciencia, de 1976 . El protagonista - que está escribiendo sus memoriasmiente tanto y tergiversa tanto su historia que en realidad no sabe ya lo que es verdad ni mentira, hasta el extremo de que se consuma un incesto, que ha ido latiendo en toda la novela, puesto que la muchacha de las bragas de oro es en realidad su propia hija.

En r982 Marsé vuelve a las aventis y a los anarquistas frustrados de los años cincuenta, con la novela Un día volveré. Todos los niños del grupo han soñado tanto con el hombre que vuelve al barrio, han oído hablar tanto de él (las aventis se cuentan a partir de las cosas oídas) que lo han convertido en un héroe legendario, una gloria del boxeo y de la guerrilla anarquista. El hombre que vuelve se llama Jan Julivert, que -se decía- había jurado volver un día, cuando saliera de la cárcel, para vengarse de aquel mundo podrido y sobre todo del juez que lo había condenado. Pero los días transcurren sin que Julivert haga nada, salvo finalmente lo que jamás esperaban los niños: ir a ver al juez pero no para matarlo sino para convertirse en su guardaespaldas. Así otro mundo se derrumba para los narradores de las aventis.

Sólo que lo que llama la atención es el nombre del juez: el juez Klein. ¿De dónde lo ha sacado Marsé? Evidentemente de la serie de novelas de José Mallorquí titulada Dos hombres buenos. Los dos hombres buenos son el español César de Guzmán -que busca a los asesinos de su esposa- y su amigo portugués el joven Joao de Silveira (que lleva revólveres con cachas de nácar y que cuando alguien le llama "mentiroso", indica siempre: "Por favor, cuando diga eso sonría"); y un tercer protagonista, un extraño personaje que jura siempre por siete (por siete cañonazos, por siete escorpiones) y que responde exactamente al nombre de juez Klein, el nombre que va a utilizar Marsé.

Dos hombres buenos (que luego se convertiría en un serial radiofónico) no es una serie tan buena como El Coyote, pues El Coyote supuso la obra maestra de las novelas populares de la época (aunque algún crítico lo considere simplemente como un tebeo: hubo tebeos del Coyote, pero lo que los niños y la gente leía por miles eran las novelas de Mallorquí). De cualquier modo no deja de ser sintomático que Marsé mezcle las novelas de quiosco de las aventis con la realidad del legendario anarquista y que el juez que aparece en Un día volveré se llame precisamente el juez Klein, como acabamos de indicar. 
Pero es que Marsé es un narrador nato, y cualquier narración le apasiona, sobre todo en aquellos inicios de los 80 donde la narración antinarrativa o la novela antinovelesca y sin argumento parecían ser una moda inevitable (al modo de Benet o del lingüisticismo francés, etc.). Quizá en esta defensa de la novela popular (algo similar a lo que reivindica el no menos barcelonés Eduardo Mendoza) Marsé esté haciendo un guiño hacia el hecho básico de que contar una novela es contar una historia. Y que lo importante es contarla bien. Precisamente lo que él sabe hacer hasta el extremo y lo que hará que en Caligrafía de los sueños nos remita continuamente a Hemingway, a Knut Hamsun y a Balzac, o sea, también a tres narradores natos.

De cualquier modo si Un día volveré es la alegoría global de una derrota, en I984 Marsé logra una alegoría global de todo su mundo y de toda la vida que alberga ese mundo: Ronda del Guinardó. En vez de un viaje interminable se trata de un breve viaje a través de su barrio, por la luz de las calles y en las sombras del metro. La historia de ese viaje es muy simple: un viejo inspector de la policía franquista, lleno de achaques físicos y cansancios vitales, va a buscar a una chica del barrio, Rosita, de trece años, para que reconozca el cadáver del hombre que la había violado cuando tenía once. La vivacidad de Rosita y el resquebrajamiento físico y moral del inspector otorgan una fuerza narrativa asombrosa a esa pequeña novela, con un final fascinante, cuando Rosita se limita a decir: "No es él". Así Ronda del Guinardó, que es como se titula, decimos, esta alegoría decisiva, se convirtió sin duda en una pequeña obra maestra.

Marsé volvería al cuento o al relato corto en 1987 , cuando decide reunir cuatro relatos breves (luego sólo tres), todos más o menos autobiográficos, y darles el título de Teniente bravo. Este relato, "Teniente bravo" parece corresponder a la época en que Marsé estaba en la mili, y trata de un teniente que se "descojona" -literalmente- al golpearse con el potro del gimnasio sobre el que intentaba enseñar a saltar a los soldados; lógicamente el teniente acabó en el hospital. Los otros dos relatos se ambientan en territorios ya conocidos: se trata de "El fantasma del cine Roxy" y de "Historia de detectives", donde vuelve a aparecer el ahorcado del barrio de la Legalidad, etc. La sátira brutal contra la "gauche divine" barcelonesa que acudía al famoso pub Bocaccio era tan explícita que ese relato ("Noches de Bocaccio") desapareció del libro a partir del año 2000.

Pero en los años ochenta y comienzos de los noventa, con la consolidación de la democracia, resurgió y se consolidó también, la cuestión de los llamados nacionalismos periféricos. Los más de treinta años que llevan mandando en la Generalitat, y la prepotencia de Jordi Pujol y sus seguidores de Convergència provocaron una sátira fantástica en Juan Marsé, una sátira esperpéntica, que oscilaba entre Valle Inclán y El Buscón de Quevedo. La titulaba El amante bilingüe y apareció en I99O, en pleno auge de la inmersión o normativización lingüística. De modo que Marsé se inventa a un personaje de la alta burguesía catalana, una chica que se llama precisamente Norma y su marido que se llama directamente Juan Marés. Todo parece funcionar perfectamente, hasta que Juan Marés se da cuenta de que su mujer lo rechaza porque no es un catalán auténtico, sino que tiene un origen dudoso. El problema del origen es siempre básico en los nacionalismos, pero 
es que en realidad también el origen de Juan Marsé es más que dudoso. Parece que Juan Marsé Carbó tenía en realidad apellidos charnegos y que se llamaba o se llama también Juan Faneca Roca. Como la historia es muy conocida y Marsé vuelve a narrarla en Caligrafía de los sueños, se puede resumir muy brevemente: su madre - ¿adoptiva?- habría tenido un hijo que nació muerto. Cuando salían del hospital ella y su marido encuentran un taxi y el taxista les cuenta una historia a la inversa: que es su mujer la que ha muerto al dar a luz a un niño en su casa. Entonces la madre sin hijo, Alberta o Berta, le habría pedido al taxista, al charnego Faneca, que la llevara a su casa para recoger al niño sin madre y que Berta habría cogido al niño en brazos y ya nunca se habría separado de él. Al menos esta es la versión que existía hasta ahora, y la versión que Marsé nos cuenta en su libro, pero Marsé parece sospechar últimamente que todo fue un invento de su madre y que aquel taxi nunca existió, de modo que en realidad sus orígenes son muy inciertos.

Pues bien, Elamante bilingüe es la historia de ese niño que crece dentro del "nacionalismo" de la democracia y se convierte en el marido de Norma. Pero Marsé, que siempre ha sido muy catalán pero poco "soberanista", hace que el marido, Marés, se aleje de su mujer, y así asume el papel de Faneca: un miserable hundido en la droga y el alcohol, pero al que Marés representa como un gitano andaluz/ catalán, incluso como un torero catalán que quiere toros catalanes, y que se ríe de las sardanas y de los toros, pero que con sus patillas a lo gitano y su acento imposible, por fin seduce a su mujer como si fuera una furcia cualquiera. Aunque su verdadero amor sea ahora una peluquera que sin imposiciones habla tranquilamente en catalán y en castellano y que según Marés tiene un corazón de oro. Les aconsejo que lean la novela antes de ver la película de Vicente Aranda.

Luego vinieron El embrujo de Shangai (I993) y Rabos de lagartija ya en el 2000. El embrujo de Shangai resulta otra maravillosa novela de amor, de aventis y de héroes que son impostores. Y vuelven a recordársenos los relatos anteriores: Rosita, en Ronda del Guinardó ha visto la película El embrujo de Shangai (de J. Von Sternberg) y no se ha enterado de nada, aunque le haya apasionado. Ahora, en esta otra novela corta, El embrujo de Shangai, Daniel, el chico protagonista ve la película al final de la novela y tampoco se entera de nada pero queda igualmente fascinado. La novela lleva una cita inicial de Luis García Montero: "No se tiene nostalgia del ayer sino del futuro". Y en realidad es una pequeña joya. Daniel, que también quiere ser músico, como el protagonista de la última novela, dibuja cada día, en el dormitorio de ella, a la rica chica tuberculosa, Susana (que ya había aparecido en Si te dicen que caí) de la que lógicamente se enamora y a la que lógicamente tendrá que renunciar, mientras que sus amigos siguen vendiendo o alquilando tebeos y novelas y viviendo en la madeja del cine y las aventis. Un vacuo anarquista les cuenta a la vez una falsa historia (que es lo que constituye la novela) sobre las supuestas aventuras del padre de Susana en Shangai. Por su parte Rabos de lagartïa, del 2000, quizá sea la novela más literaturizada de Marsé, aunque ya en este Marsé literatura y realidad resultan idénticas. Se basa en el Tristram Shandy, de L. Sterne, porque Víctor Bartra (desde el útero materno, aún sin nacer) nos cuenta como su hermano David (que corta rabos de lagartija porque no sale sangre) se esfuerza para que su madre y un inspector 
franquista no acaben liándose, un lío sin resolver como en el propio Sterne. De distinto estilo es Canciones de amor en el Lolita's Club (2005), una novela actual donde se mezclan etarras y narcotraficantes gallegos, etc.

Y así llegamos al final: Caligrafía de los sueños ${ }^{4}$.

En realidad es un conjunto de cuentos que nos preparan para una novela corta que se desarrolla a partir de la página 230, a partir del capítulo II.

O mejor dicho:

Es una novela de enigmas, que se basa en uno de los enigmas literarios más conocidos: ¿qué hacía el esqueleto de un leopardo en lo más alto de las nieves de las montañas del Kilimanjaro? Ese enigma propuesto por Hemingway obsesiona al protagonista y obsesiona a toda la novela. Así el primer cuento, o el primer capítulo, implica un primer enigma ¿por qué la señora Mir ha salido gritando de su casa y se ha tumbado para suicidarse sobre los raíles de un tranvía? El enigma visible es que esos raíles de tranvía no sirven para nada, hace años que la calle se asfaltó, que el tranvía no pasa por allí y sólo queda el resto de esos raíles que incomprensiblemente permanecen en la calle. El segundo enigma es por qué la señora Mir mira continuamente al balcón de su casa, si dice que allí no hay nadie y que su hija se ha ido a la playa. Lógicamente es lo que Hemingway (a quien el protagonista lee en las páginas 2I y 22) llamaba -como quizá ustedes sepan- la técnica de la punta del iceberg: en un relato sólo se debe ver esa punta y dejar entrever apenas la inmensa mole de hielo que hay por debajo. Advierto que la novela comienza un domingo del mes de Junio (luego nos enteramos que de i948) y termina un domingo de agosto de I958. O sea, diez años después.

El segundo capítulo o relato se titula "Una plaga de ratas azules” y comienza con una frase del padre del protagonista que es en realidad un verso de Jaime Gil de Biedma: “este país de todos los demonios”. El padre de Mingo (un Pep Marsé que aquí no está idealizado, como lo estaba el padre en las otras novelas) es jefe de una brigada de raticidas del Ayuntamiento y habla siempre de las ratas azules, que para el niño son otro enigma: nunca ha visto ratas azules. Está claro que las ratas azules son los falangistas, lo mismo que los curas son las ratas negras. Y por eso el padre mantiene una discusión con un cura en un tranvía. El tercer capítulo o relato se titula: "Apaches galopando en las playas de Arizona”. Es una magnífica aventi sobre los apaches y una chica prisionera de los indios y donde todo el grupo quiere participar, hasta que el único del grupo que va al colegio le dice a Ringo que la aventi no funciona porque en realidad Arizona no tiene playas. Pero Ringo encuentra otro enigma: los tres peldaños que nadie sabe cómo se construyeron, ni para qué, ni qué hacen en la ladera de aquel monte pelado. Y Marsé nos presenta así

${ }^{4}$ Caligrafía de los sueños, Lumen, Barcelona, 20Ir. Todas las referencias que se hacen en el texto remiten a esta edición. 
a Ringo ante los escalones, en la página 69: "Hola, enigma, susurra”. El cuarto relato o capítulo se titula "El sobre color de rosa". Ahí Hemingway aparece citado en las páginas 8o, 8I y 96. Pero el verdadero enigma es el del sobre: el señor Alonso, el viejo tranviario o futbolista del C.D. Europa, el equipo del barrio, que se había tenido que retirar por una grave lesión y que ha sido el amante de Victoria, o sea, de la señora Mir, este señor Alonso habría escrito una carta en papel rosa y la había metido dentro de un sobre rosa que le había proporcionado la tabernera del bar bodega Rosales. Paquita, la tabernera, se lo cuenta a Victoria y le dice que cualquier día le llegará ese sobre que llevaba simplemente dibujada una $\mathrm{V}$ como dirección. A partir de aquí la señora Mir o Victoria comenzará a buscar obsesivamente esa carta y ese sobre. El capítulo cinco se titula "El dedo del destino". Aquí el protagonista aparece leyendo Piel de zapa, de Balzac, y Hambre, de Knut Hamsun, pero el Kilimanjaro vuelve a aparecer en la página I37 (y Hambre en la I38). El problema ahora es el enigma de la vida para el protagonista: ha perdido el dedo índice en el taller de joyería donde trabajaba, él lo llama "el suicidio del dedo", pero así se rompe su vocación de pianista para siempre. El capítulo sexto lleva un título de Hemingway también "El gorrión bajo la lluvia" (en Hemingway es un gato). Aquí el enigma es primero el de la muerte: con diez años mata a un gorrión y no lo puede olvidar nunca. Pero también el de la vida: cuando su abuela lo lleva a la escuela en el pueblo el niño se entera de todo respecto a su nacimiento, la historia del taxi, etc. El capítulo diez "Caligrafía de los sueños”, comienza con una variante de la cita de Hemingway de Las nieves del Kilimanjaro y el enigma del esqueleto del leopardo allí perdido. Y termina con el primer cuento escrito por el protagonista: un cuento que es un calco de ese comienzo del Kilimanjaro, sólo que el enigma son ahora los tres escalones y no el leopardo.

El resto de la novela obviamente no lo voy a contar. Sólo me referiré al epílogo, titulado "Los pasos erráticos del mensajero", donde diez años después, en la piscina del Club natación Cataluña, el protagonista Ringo, que ya es un joven veinteañero que ha publicado dos relatos y espera escribir su primera novela, se encuentra con el señor Alonso, que trabaja como barrendero en el club. Allí se resuelve el enigma de la V en el sobre y toda la tragedia de la novela. $\mathrm{Al}$ menos en apariencia. La verdadera " $\mathrm{V}$ " de la carta rosada no es la madre (Victoria) sino la hija (Violeta) que no sabemos si fue violada por el señor Alonso o fue ella quien "lo violó", quitándole así el novio a la madre. En este "universo" todo el mundo es un yo sin yo-soy, excepto Violeta (que consigue ser enfermera titulada) a fuerza de imposturas - como el Pijoaparte o el Java- y excepto los ricos, claro.

Pero lo que nunca sabremos es lo que pintaba el esqueleto del leopardo en las nieves del Kilimanjaro ni lo que pintaban los tres peldaños en la ladera del monte pelado del Carmelo. Ese es posiblemente el final que yo quería contarles: que quizá jamás descubriremos el enigma del "Universo Marsé”, como jamás descubriremos el enigma de la caligrafía de nuestros sueños.

Así pues: "Hola, enigma". 